\title{
ORGANIZATIONAL PRINCIPLES AND CONTENT OF EARLY FOREIGN LANGUAGE LEARNING IN THE USA
}

\begin{abstract}
According to the results of leading American scientists that convincingly demonstrate the effectiveness and necessity of early foreign language learning the features of teaching foreign languages at elementary level in the United States have been analyzed. It has been found out that the US government is working on the improvement of foreign language at elementary education all over the country. The attention is paid the languages that were not so popular, and now have obtained the status of "extremely necessary", such as Arabic, Farsi and Russian, as they have become very important for the future participation of the state in world politics. The requirements for programs development of foreign language for elementary school have been described; such aspects as quantity of classes, curriculum project, teaching materials, teaching staff and knowledge of the students, the choice of languages, coordination and efficiency are taken into consideration. The short description of the content of foreign language teaching of elementary education has been presented. It has been indicated that success in foreign language learning as a device of foreign language communication depends on the level of listening, lexical, grammatical and spelling skills, as well as the abilities of listening, speaking, reading and writing, which are defined in the program for elementary school.

Key words: foreign language education, foreign language, American school, elementary school, curriculum, requirements, abilities, skills.

\section{INTRODUCTION}

Currently the United States of America, creating a tolerant community, along with other highly developed countries have set a series of challenges in the scope of political, economic, social, cultural, and education issues. One of the priorities is to create a common language space which resulted in a great attention of international and national official and public organizations and associations to solve the problem of language teaching at all levels. It stands to reason that at the 32nd General Conference of UNESCO in Paris (1998) during the Round Table Discussion called "The quality of education promotion" among the World Ministers of Education there was stressed that a good education is impossible without a good command of state or native languages, and one or two foreign languages, mostly spoken in the world.

Therefore it has led to significant changes in the paradigm of "foreign language" taught at all stages of education in the USA, elementary school as well. Unfortunately, a few decades ago, teaching foreign language in American schools was optional or started at high school. Today, in this country an educational sector "Foreign Language" plays a special role along with other humanities in the development of young individuals, especially the role of early foreign language learning is highlighted.
\end{abstract}




\section{THE AIM OF THE STUDY}

In the article we try to analyze the characteristics of foreign languages studying at an early stage in the USA on the basis of the results of leading American scientists studies that demonstrate the effectiveness and necessity of early foreign language learning, and it is also necessary to set out the requirements on foreign language programs creation for elementary school and to share the main characteristic of foreign language content of elementary education.

\section{THEORETICAL FRAMEWORK AND RESEARCH METHODS}

The theoretical basis of the study are the works of American scholars on the problems of foreign language teaching in elementary school, where the positive results of early foreign language learning and its impact on the academic achievements of students in other subjects are highlighted. So, P. Armstrong and J. Rogers present qualitative and quantitative indicators of elementary school students' achievement in learning a foreign language and as a result the improvement of their mathematics, reading and native language skills (Armstrong, Rogers, 1997). The effectiveness of the foreign language program being in practice at Louisiana Elementary School and its impact on the students' intellectual development are described by K. Foster and C. Reeves (Foster, Reeves, 1989). Such scholars as A. Garfinkel and K. Tabor carried the study in which elementary school students with intermediate level demonstrated significantly better achievements in English reading after visiting their voluntary foreign language classes in their free time (Garfinkel, Tabor, 1991).

To achieve the established aim the following methods have been used: studying, analysis and generalization of foreign scientific literature dedicated to the problem, synthesis, comparison and generalization.

\section{RESULTS}

The most of American scientists suggest that the foreign language learning at an early stage in the United States of America was very far from international standards for a long time. Thus, the Center for Applied Linguistics report in 2008 indicated that only $25 \%$ of elementary schools studied a foreign language, where state schools amounted only to 15 $\%$. In addition the US Department of Education reports that while 200 million of Chinese students are studying English, which is compulsory for all elementary school students, only 24 thousand of 54 million of American children are studying the Chinese language at elementary school (U.S. Department of Defense, 2004).

However, the US government is working on the improvement of foreign language elementary education through all the country. The focus is on the languages that were not popular, but now have the status of "extremely necessary languages" such as Arabic, Farsi and Russian, which have become extremely important in the future of US involvement in the world politics. Early foreign language learning also affects the development of cognitive abilities, academic achievements, letting children get acquainted with other cultures, which effect the development of positive attitudes towards diversity.

The necessity of teaching foreign language in elementary school is stressed by Mary Lynn Redmond, a director of foreign language education at Wake Forest University, and an Executive Secretary of the National Network of early language learning: "Children should start learning foreign language in kindergarten and continue during the years of schooling. Language learning helps improve the skills of listening, memory, creativity and critical thinking that comprise an intellectual process that affects learning in general" (Walker, 2004). She also declares that younger children learn foreign languages more easily than older or adults, and emphasizes on the continual consistent study of language to achieve 
such level of knowledge that is required to communicate with people around the world. The scientist says that "nowadays parents understand the importance of early foreign language learning in the development of mental abilities of the child. But most officials still stuck to the point, as 25 years ago, to ignore the latest researches of neurologists on the role of foreign language in mental development" (Walker, 2004).

If a child studies at elementary school where there is not any foreign language program Redmond advises parents to get to know about such programs in other schools, paying attention to the number of foreign language classes and how these classes correspond with the content of other subjects such as mathematics, sciences, and social discipline. Then parents can apply for the implementation of foreign language learning program into the curriculum of the school, their child studies at (Walker, 2004).

According to the Report of Applied Linguistics Center for 2008, the most popular foreign languages in elementary school are French and Spanish. However, positive changes are in learning Chinese and Arabic.

American scientists warn that schools that are going to introduce new foreign languages programs in elementary schools should be well-informed about the factors that led to the termination of the programs of 1950-60s, and as those factors still have an effect on the effectiveness of such programs. Among them are: insufficient number of teachers possessing appropriate language skills and qualifications to teach a foreign language at an early stage; unreal program goals; the lack of coordination at various levels of studying; discrepancy of teaching methodology for elementary school pupils; inadequate and insufficient teaching materials; the lack of students' knowledge evaluation, teachers work and the effectiveness of programs.

As US experts say, if the school has decided to implement a foreign language program at an early stage, the first thing to do is to create a Commission that would control this process. Such a commission should include all those, who are involved in the program implementation: parents, teachers, foreign language teachers, class-teachers, administrators of elementary and middle schools, LEA and community members. The Commission aims are to solve the following problems:

1) to examine the feasibility of early foreign language learning before the program for elementary school implementation;

2) to review the professional literature (including research results), consulting specialists in language and attending working programs, to explore the advantages and limitations of each program model;

3) to examine the foreign language curriculum and teaching strategies at elementary school, to find out the status of foreign language studying at early level;

4) to analyze the foreign language curriculum at each level (elementary, middle, high school) in order to provide continual consistent studying that promote better mastering the language;

5) to evaluate foreign language programs working at a particular school area to consider this information to further programs development;

6) to inform teachers and administrators, parents and the public about the effectiveness of foreign language program in elementary school, teaching strategies used at the level, and results of different program models;

7) to determine the level of foreign language program support at elementary level by school, parents, businesses and community; 
8) to identify the most productive program models for local application through philosophy of foreign language teaching and the results of developed programs discussion (Rosenbusch, 1991).

As to the researches of M. Met, N. Rhodes and M. Rosenbusch, at the foreign language program development for elementary school it is important to pay special attention to structural components such as number of classes, curriculum project, teaching materials, teaching staff and students level of knowledge, language choice, coordination and efficiency. Two of the most important aspects are the amount of classes and the choice of language. The first aspect implies that the least amount of time for language in elementary school is 75 minutes a week that is one lesson a day (Rosenbusch, 1995). M. Matt and N. Rhodes suggest that "foreign language teaching should be done every day and not less than 30 minutes" (Met, Rhodes, 1990).

The most controversial moment in the development of the program is the problem of choosing the language to study (Met, 1989). This problem solving should take into account the availability of teachers, program organization and the number of classes, the ability to use language program at a further stages and linguistic diversity.

If the committee determines that the main goal of the program is to master a high level of foreign language by students, so she suggests that language studying process should start as early as possible to maximize the time and intensity of the program at every level, and the program should be consistent, which will provide continuous training at all stages.

As M. Matt and N. Rhodes state, students will be able to continue language learning at each stage and will be able to start learning a second foreign language or change the language in the early middle or high school. All students study a foreign language, "despite the style, level of achievement, ethnic or racial origin, social and economic status, native language or future objectives of education" (Met, Rhodes, 1990).

Thus teachers at all stages of education should possess excellent language skills, to be well-informed on modern teaching strategies and techniques and work as a team to provide consistent curriculum.

During last decades foreign language teaching at American elementary school starts at the first grade (sometimes pre-school) and lasts for four years. In some schools the initial stage of foreign language learning covers grades from 5 to 8 , because that is the time to start the studying of this subject.

At an early stage of foreign language learning the basis of foreign language are taught. The continued success in a foreign language as a means of foreign language communication by the students depends on the level of formation of lexical, grammatical and spelling skills, and abilities of listening, speaking, reading and writing, as it is defined in the program.

The scope of teaching material at this stage of foreign language learning must be sufficient to set the basis of each type of speech activity at basic communicative level. Students study phonetics, writing, and grammar rules.

The effectiveness of elementary teaching affects the formation of types of speech activity. American researchers in the field of foreign language teaching at elementary school (D. Brown, S. Lins) emphasize that all forms of speech activity are interdependent components of speech practice. Mastering different aspects of language (phonetic, lexical, and grammatical) does not occur in isolation, but integrated.

At this stage students learn comprehensive listening, make small messages, participate in the conversation. Here, the most important place is devoted to the methods, 
aimed to the development of listening skills that is the key for improving language skills and other main way through which the student makes the initial contact with the language and culture studied. A special step to expand learning opportunities of listening is creating a language space in the classroom, where communication takes place in a foreign language. Every time the teacher speaks the language, students practice it through listening.

According to the American specialists in the field of elementary foreign language learning, the development of speaking skills at the communicative lesson usually is not a separate task that can be done in isolation, without the development of other skills. The objective of speaking teaching at elementary school is to develop the ability to make oral communication in different situations according to their actual needs and interests. In the early stages of language mastering children are taught elementary basic phrases to express a request, to clarify or comment, to ask a question (Curtain, Dahlberg, 2004).

Learning to read and write at an early stage of foreign language learning usually starts at the end of 2 nd grade and is based on lexical and grammatical material. At the same time the task is to master the technique of reading aloud and silently with a full understanding of the content. American specialists pay special attention to the point when to start teaching reading and how to combine it with the other types of speech activity, especially of oral speech.

Teaching reading is tightly connected with teaching speech and writing. The information got during reading is used in speech and writing when doing after-reading exercises. At early stage of learning a foreign language students master writing and foreign language spelling, using writing as a means of fixation of foreign material and make small written messages. For a long time in the history of American methods of teaching writing in a foreign language has been of secondary importance, often reduced to such language skills as spelling and grammar correctness. However, in recent years the situation has changed: within the curriculum, which is thematic, communicative and directed to transfer meaning, students use writing for different purposes depending on the nature of the message they want to convey the audience. It should be noted that American specialists point out writing for communication and writing for publication.

The results of methodological research and many years of American teachers indicate that speaking is of top priority at early stage of learning language. The skills of speech have a positive impact on the skills development in all types of speech activity. The combination of visual and imaginative thinking, the ability to think abstractly and to generalize creates favorable conditions for foreign language learning at this stage.

An essential feature of the early period of foreign language learning is that here is a special academic (cognitive) motivation. The laws of forgetting, that are active, come into force when the students have learned considerable material and continue to learn new one. Everything that has been reviewed is new and it does not conflict with the old. Although a significant impact at this stage has the native language, but interlingual interference has still appeared.

\section{CONCLUSIONS}

Thus, at this stage researchers and practitioners L. Anderson, D. Ausubel, J. Block, B. Bloom, who study languages, noted that one of the main trends of modernization of the early foreign language learning content in modern American schools are: the principles of individual approach, in which the leading role is given to the principle of complete mastering of program material; preparation for the "dialogue of cultures" that includes: knowledge of basic cultural characteristics of nations and nationalities living in the United States of America and abroad, multilingualism and linguistic world of modern human 
rights; learning to learn, including: mastering technology to acquire oral and written information of sociocultural character from various sources, summarizing the material, organize and summarize it in the form of diagrams, tables, charts; the usage of a foreign language as a device of teaching other subjects.

The study does not conclude all the aspects of the problem. Perspective directions for further studying can be various program models application of bilingual learning at the elementary level of the foreign language studying, organizational and pedagogical foundations, content and foreign language teaching methodology in middle and high schools, the problem of foreign language education continuity and consistency in US middle schools.

\section{REFERENCES}

1. Armstrong, P. W. \& Rogers, J. D. (1997). Basic Skills Revisited: The Effects of Foreign Lsnguage Instruction on Reading, Math and Language Arts. Learning Languages, No 2, p. 20-31.

2. Curtain, H. \& Dahlberg, C. A. (2004). Languages and Children, Making the Match : Foreign Language Instruction for an Early Start Grades K-8. NY : Longman, p. 480.

3. Foster, K. M. \& Reeves, C. K. (1989). FLES Improves Cognitive Skills. FLES News, No 2, p. 4

4. Garfinkel, A. \& Tabor, K. E. (1991). Elementary School Foreign Languages and English Reading Achievement: A New View of the Relationship. Foreign Language Annals, No 24, p. 375-382.

5. Met, M. (1989). Which Foreign Language Should Students Learn? Educational Leadership, No 7, p. 54-58.

6. Met, M. \& Rhodes, N. (1990). Priority: Instruction. Elementary School Foreign Language Instruction: Priorities for the 1990s. Foreign Language Annals, No 23, p. 433-443.

7. Rosenbusch, M. (1991). Elementary School Foreign Language: The Establishment and Maintenance of Strong Programs. Foreign Language Annals, No 24, p. 297-314.

8. Rosenbusch, M. (1995). Language Learners in the Elementary School: Investing in the Future. In: Donato, R. \& Terry, R. (Eds.) Foreign Language Learning, the Journey of a Lifetime. Lincolnwood, IL: National Textbook, p. 1-36.

9. U.S. Department of Defense. National Language Conference Results Announced. (2004). Retrieved 08.12.2014 from : www.defenselink.mil/releases/2004/nr200406290953.html.

10. Walker, Ch. (2004). Foreign Language Study Important in Elementary School. Retrieved 01.10.2014 from : www.wfu.edu/wfunews/2004/062404r.html. 